\title{
ACÚMULO DE ANTOCIANINAS E CARACTERÍSTICAS FÍSICAS E QUÍMICAS DE FRUTOS DE LARANJAS SANGUÍNEAS DURANTE O ARMAZENAMENTO A FRIO ${ }^{1}$
}

\author{
RODRIGO ROCHALATADO², PAOLACHRISTOVAM TOGNATO ${ }^{3}$, MARIAESTELA SILVA-STENICO $^{4}$, \\ LENICE MAGALI DO NASCIMENTO ${ }^{2}$, PEDRO CÉSAR DOS SANTOS $^{5}$
}

RESUMO - Este trabalho teve como objetivo avaliar o conteúdo de antocianinas no suco e as características físicas e químicas dos frutos de oito variedades de laranjas sanguíneas e de laranja Valência, e, também, verificar os efeitos do armazenamento dos frutos a $10^{\circ} \mathrm{C}$, durante um período de até 60 dias, nos parâmetros avaliados. Os teores de antocianina foram determinados utilizando-se de um método espectrofotométrico, assim como dez características físicas e químicas dos frutos e dos sucos foram avaliadas antes e durante o armazenamento. Todas as variedades de laranja avaliadas apresentaram naturalmente baixos teores ou nenhum teor de antocianina no suco. $\mathrm{O}$ armazenamento durante um período de até 60 dias, em baixa temperatura, possibilitou acúmulo significativo de antocianina no suco, porém de maneira desigual nas variedades de laranjas sanguíneas testadas. As variedades Moro foram as que apresentaram suco contendo os maiores teores de antocianina no final do armazenamento. À exceção de duas variedades, Sanguinelli (Marrocos e Polidari), as demais variedades sanguíneas avaliadas podem ser consideradas como semelhantes entre si e adequadas ao consumo. $\mathrm{O}$ armazenamento dos frutos a $10^{\circ} \mathrm{C}$, durante o período máximo de 60 dias, alterou significativamente somente as variáveis: largura de frutos, teor de SS, acidez e o rendimento de suco.

Termos para indexação: Citrus sinensis, antocianina, fruto, suco, conservação, frio.

\section{ACCUMULATION OF ANTHOCYANINS AND CHARACTERISTICS OF FRUITS OF BLOOD ORANGES DURING COLD STORAGE}

ABSTRACT - The aim of this study was to assess the content of anthocyanins in the juice and the physical and chemical characteristics of the fruit of eight blood orange varieties and of orange Valencia, and also verify the effects of storage of fruits at $10^{\circ} \mathrm{C}$, for a period of up to 60 days, in the same parameters. The anthocyanin content was determined using a spectrofotometric method and ten physical and chemical characteristics of the fruits and juice were also evaluated before and during the storage. Under natural conditions all varieties showed fruits with low anthocyanin content in the juice. Cold storage during a period of up to 60 days enables a significant accumulation of anthocyanin in the juice, but in a different level in the evaluated blood orange varieties. Moro is the variety that showed the highest anthocyanin content in the end of the storage period. Except for two Sanguinelli varieties (Morocco and Polidari), the other varieties can be considered as similar as others and suitable for consumption. The storage of fruits to $10^{\circ} \mathrm{C}$ during the maximum period of 60 days significantly modifies only fruit width, juice content in fruits, soluble solids content and acidity of the juice.

Index terms: Citrus sinensis, anthocyanin, fruit, juice, cold storage.

\section{INTRODUÇÃO}

De acordo com a classificação proposta por Bitters (1961), as laranjas podem ser divididas em dois grandes grupos, em função da sua coloração: as laranjas douradas e as laranjas sanguíneas. As laranjas douradas seriam caracterizadas pela cor laranja da polpa e do suco, devido à presença de carotenóides, pigmentos que variam entre o amarelo e o vermelho. Já as laranjas sanguíneas seriam caracterizadas pela coloração vermelho-intensa (violácea) da polpa e do suco, devido à presença de antocianinas (Bitters, 1961).

As antocianinas são pigmentos solúveis em água, pertencentes à família dos flavonóides (Winkel-Shirley, 2001).
Em plantas, podem ser encontradas em flores, frutos, folhas, caules e sementes, tendo como funções: a atração de polinizadores, a dispersão de sementes, a proteção contra danos provocados pela luz UV e contra o ataque de patógenos (WinkelShirley, 2001; Field et al., 2001). As antocianinas apresentam grande importância na dieta humana, podendo ser consideradas como agentes terapêuticos, por possuírem capacidade protetora contra o estresse oxidativo, doenças do coração, certos tipos de cânceres e outras doenças relacionadas, e também, pela sua capacidade de inativar radicais livres (Ross \& Kasum, 2002).

As laranjas sanguíneas são originárias da região Mediterrânea, provavelmente de Malta ou da região da Sicília (Itália), e têm sido cultivadas há vários séculos, principalmente na Itália, Espanha, Marrocos, Argélia e Tunísia (Saunt, 1990). Na

${ }^{1}$ (Trabalho 203-07). Recebido em.: 21-08-2007. Aceito para publicação em: 10-04-2008

${ }^{2}$ Pesquisador do Centro APTA Citros Sylvio Moreira/IAC, Rod. Anhanguera, Km. 158, Cx. Postal 04, CEP 13490-970, Cordeirópolis-SP. rodrigo@centrodecitricultura.br, lenice@centrodecitricultura.br

${ }^{3}$ Engenheira Agrônoma, estagiária do Centro APTA Citros Sylvio Moreira/IAC. P tognato@yahoo.com.br

${ }^{4}$ Pós-Doutoranda do Laboratório de Biologia Celular e Molecular - CENA/USP, Av. Centenário, 303, CEP 36.570-000, Piracicaba-SP. estela@cena.usp.br ${ }^{5}$ Docente da UNESP Ilha Solteira, CEP 13490-970, Ilha Solteira-SP. santospc@agr.feis.unesp.br 
Itália, o grupo das laranjas sanguíneas, tais como a Moro, Tarocco e Sanguinello, constitui aproximadamente $70 \%$ da produção total de laranjas (Rapisarda \& Giuffrida, 1992; Rapisarda et al., 2001). No Brasil, elas ainda não apresentam interesse comercial, porém, devido ao seu potencial como alimento funcional, seria interessante realizar mais estudos visando à introdução do seu cultivo no País.

Estudos prévios demonstraram que a síntese e o acúmulo de pigmentos em laranjas sanguíneas têm controle genético, mas podem sofrer grande influência ambiental. Rapisarda \& Giuffrida (1992) comprovaram que variedades de laranjas sanguíneas possuíam distintas capacidades de acumular antocianinas nos frutos, quando cultivadas num mesmo local. Verificaram também a existência de uma correlação positiva e significativa entre o conteúdo de antocianina e o estádio de maturação dos frutos. Meredith \& Young (1969), trabalhando com apenas uma variedade de laranja sanguínea, cultivada em diversas temperaturas, verificaram que o acúmulo de antocianinas nos frutos é influenciado positivamente pelo cultivo das plantas em condições de temperaturas mais baixas. Também Bitters (1961) verificou que o cultivo de laranjas sanguíneas em regiões com clima de dias quentes e noites frias favorecia a produção de frutos com polpa de coloração mais intensa.

Uma característica interessante das laranjas sanguíneas é a possibilidade de incrementar a concentração de antocianina nos frutos e no suco, por meio da conservação pós-colheita dos frutos em baixas temperaturas. Rapisarda et al. (2001) observaram o acúmulo de antocianinas em frutos de três variedades de laranjas sanguíneas, quando conservados em temperatura de $8^{\circ} \mathrm{C}$, durante 80 dias. Lo Piero et al. (2005) também obtiveram resultados semelhantes com frutos de laranja Tarocco, quando conservados a $4^{\circ} \mathrm{C}$ durante o máximo de 75 dias.

Os objetivos do presente trabalho foram a avaliação do conteúdo de antocianinas no suco dos frutos e das características físicas e químicas de frutos e de suco, de oito variedades de laranjas sanguíneas e da laranja Valência, cultivadas no município de Cordeirópolis (SP), bem como a avaliação dos efeitos do armazenamento dos frutos a $10^{\circ} \mathrm{C}$, durante até 60 dias, sobre o acúmulo de antocianinas no suco e na manutenção das características de fruto e de suco.

\section{MATERIAL E MÉTODOS}

Para realização deste estudo, foram utilizados frutos das seguintes variedades de laranjas sanguíneas: [Moro Palazelli (CN 44), Moro Acireale-2 (CN 46), Moro-4 (CN 77), Sanguinelli Acireale (CN 61), Sanguinelli Marrocos (CN 73), Sanguinelli Polidari (CN 74), Tarocco Acireale (CN 65) e Tarocco (CN 67)] e como controle utilizaram-se frutos de laranja Valência.

Aproximadamente 200 frutos de cada variedade foram colhidos de plantas do Banco Ativo de Germoplasma do Centro APTA Citros Sylvio Moreira/IAC, em Cordeirópolis (SP), em 0808-2006. As plantas com idade de 17 anos foram cultivadas sem irrigação e utilizou-se a tangerina Cleópatra como porta-enxerto. Após a colheita, os frutos foram lavados com água corrente, desinfectados superficialmente por meio de imersão durante cinco minutos, numa solução aquosa de hipoclorito de sódio a $5 \%$. A seguir, foram colocados em bandejas plásticas para a secagem em temperatura ambiente e, então, acondicionados em caixas de papelão, modelo telescópio, tipo para exportação de citros. As caixas foram armazenadas em câmara fria a $10^{\circ} \mathrm{C}$, com umidade relativa do ar de 70 a $80 \%$ e sem nenhum controle atmosférico, durante um período máximo de 60 dias.

A quantificação de antocianinas no suco dos frutos foi realizada conforme a metodologia descrita a seguir: no primeiro dia (data da colheita) e a cada 15 dias, durante o período de armazenamento, foram tomadas, aleatoriamente, três amostras de seis frutos de cada variedade, as quais foram processadas separadamente.

O suco dos frutos de cada amostra foi extraído, homogeneizado e tomou-se uma alíquota de $15 \mathrm{~mL}$ desta solução, a qual foi filtrada com peneira plástica fina e centrifugada a 6.000rpm, durante 15 minutos. Tomou-se uma alíquota de $7 \mathrm{~mL}$ do sobrenadante de cada amostra, que foi usada para a quantificação do teor de antocianinas presentes, segundo o método dois, descrito por Rapisarda et al. (2000) e citado a seguir. De cada amostra, tomou-se uma alíquota de $2 \mathrm{~mL}$ de suco centrifugado, a qual foi diluída para $25 \mathrm{~mL}$, adicionando-se $23 \mathrm{~mL}$ de solução de pH 1,0 (125mL de solução 0,2M de KCle $375 \mathrm{~mL}$ de solução $0,2 \mathrm{M}$ de $\mathrm{HCl}$ ). Uma segunda alíquota de $2 \mathrm{~mL}$ de suco foi diluída para $25 \mathrm{~mL}$, com a adição de $23 \mathrm{~mL}$ de solução de pH 4,5 (200 mL de solução $1 \mathrm{M}$ de acetato de sódio, $120 \mathrm{~mL}$ de solução $1 \mathrm{M}$ de $\mathrm{HCl}$ e $180 \mathrm{~mL}$ de água). As absorbâncias de ambas as soluções foram medidas em espectrofotômetro da marca Bel Photonics, com luz halógena de Tungstênio, no comprimento de onda de $510 \mathrm{~nm}$.

A concentração de antocianina em cada amostra foi calculada pela equação: $\mathrm{C}=\left(\mathrm{Abs}_{\mathrm{pH}(1,0)}-\mathrm{Abs}_{\mathrm{pH}(4,5)}\right) \times 484,82 \mathrm{x}$ $1.000 / 24.825$ x 12,5, onde $C$ era a concentração de antocianina expressa em $\mathrm{mg} / \mathrm{L}$ de suco; o termo entre parênteses era a diferença entre as absorbâncias medidas de cada amostra após a adição das soluções de $\mathrm{pH}$ 1,0 e de $\mathrm{pH} 4,5 ; 484,82$ era a massa molecular do cloreto de cianidina-3-glucosídio; 24.825 era a absorbância molar $(\in$ ) do cloreto de cianidina-3-glucosídio (em $510 \mathrm{~nm}$ ) em solução de pH 1,0, e 12,5 era o fator de diluição utilizado.

Os ensaios de avaliação de conteúdo de antocianinas no suco de frutos armazenados foram conduzidos em delineamento inteiramente ao acaso, com nove tratamentos (variedades) e cinco tempos de armazenamento (dias 0; 15; 30; 45 e 60), em esquema fatorial, com três repetições por variedade, em cada tempo. Inicialmente, fizeram-se análise de variância e o teste $\mathrm{F}$, seguidos da análise das variedades em cada tempo, e a análise de tempo em cada variedade, para desdobramento da interação variedade $\mathrm{x}$ tempo de armazenamento. Neste caso, em cada tempo, as médias das variedades foram agrupadas usando o teste Scott-Knott, a $5 \%$ de probabilidade. Para o fator tempo, foram feitas análises de regressão polinomial para cada variedade.

As avaliações das características físicas e químicas dos frutos e do suco foram realizadas de forma diferente. No primeiro dia (dia da colheita) e a cada 30 dias de armazenamento, retirouse ao acaso outra amostra de dez frutos de cada variedade. As variáveis físicas avaliadas para os frutos foram a massa, altura e 
largura. A partir dos dados obtidos, calcularam-se também a relação altura/largura de frutos (A/L) e o número de frutos por caixa de $40,8 \mathrm{~kg}$, por meio da fórmula: $40.800 /$ massa média de um fruto.

Após as avaliações físicas dos frutos, o suco de cada amostra foi extraído manualmente em extratora residencial e, a partir dele, avaliaram-se as seguintes características: massa do suco, teor de sólidos solúveis (SS), acidez titulável (AT) e teor de ácido ascórbico. Para cada amostra, calcularam-se também o ratio do suco (relação SS/AT) e o rendimento de suco [(massa média do suco de dez frutos/massa média de dez frutos)x100].

O teor de sólidos solúveis foi determinado em refratômetro, e os valores, expressos em graus Brix. A acidez titulável foi determinada utilizando-se de metodologia citada por Reed et al. (1986), ligeiramente modificada. Realizou-se a titulação de solução de $\mathrm{NaOH}(0,3125 \mathrm{~N})$, em solução formada por $25 \mathrm{~mL}$ de suco da fruta diluído em aproximadamente $100 \mathrm{~mL}$ de água e $1 \mathrm{~mL}$ de fenolftaleína, até atingir o $\mathrm{pH} 8,2$. A acidez titulável foi calculada pela fórmula: acidez $=$ volume de $\mathrm{NaOH}(\mathrm{em} \mathrm{mL})$ gasto na titulação $\mathrm{x}$ fator de correção da diluição $(0,08)$.

O teor de ácido ascórbico presente no suco dos frutos foi quantificado de acordo com a metodologia descrita pelo Instituto Adolfo Lutz (1985), com algumas modificações citadas a seguir. Em $50 \mathrm{~mL}$ de suco de laranja, foram acrescentados $10 \mathrm{~mL}$ de solução $0,1 \mathrm{~N}$ de ácido sulfúrico e $3 \mathrm{~mL}$ de solução de amido $0,6 \%$. Titulou-se a amostra com uma solução de iodo (18g de iodeto de potássio e $6,35 \mathrm{~g}$ de iodo ressublimado, dissolvidos em 1L de água), até o ponto de viragem para a cor verde-escura. A quantidade de ácido ascórbico foi expressa em $\mathrm{mg} / 100 \mathrm{~mL}$ de suco, utilizando-se da seguinte fórmula: (quantidade de ácido ascórbico $=$ volume de solução de iodo gasto $(\mathrm{mL})$ x 8,806).

Os ensaios de avaliação de características físicas e químicas de frutos e de suco de frutos armazenados foram conduzidos em delineamento experimental de blocos ao acaso, com três repetições. Os nove tratamentos (variedades) foram avaliados nos três tempos (dias 0; 30 e 60), com uma repetição por variedade, em cada tempo. Assim, cada tempo funcionou como um bloco estatístico. Neste caso, diferenças entre blocos indicam variação no comportamento geral das variedades em relação ao tempo de armazenamento a frio. Para cada variável, procederam-se a análise de variância e o teste $\mathrm{F}$. As médias das variedades foram agrupadas usando o teste Scott-Knott, a 5\% de probabilidade, de dois modos: 1) comparando-se as variedades, utilizando-se dos dados médios de cada variedade nos três tempos, e 2) comparando-se os tempos, utilizando-se dos dados médios do conjunto das variedades, em cada tempo.

\section{RESULTADOS E DISCUSSÃO}

A análise estatística dos resultados obtidos com os teores de antocianina presentes no suco dos frutos das nove variedades de laranja, nos diversos tempos de armazenamento, demonstrou a existência de interação significativa entre os fatores variedades e tempo de armazenamento $(\mathrm{F}=4,03$ significativo a $1 \%$ de probabilidade). Sendo assim, as variedades foram comparadas entre si quanto à concentração desse pigmento em cada tempo, assim como os tempos foram analisados em cada variedade.

Para o dia zero (frutos sem armazenamento), a avaliação do conteúdo de antocianina presente nos frutos demonstrou que, dentre as oito variedades de laranja sanguínea avaliadas, sete apresentaram frutos com suco contendo baixos teores de antocianina (entre 0,2 e 13,0mg/L). Já a laranja Sanguinelli Acirealle (CN 61) e a variedade-controle (laranja Valência) não apresentaram antocianina nesta data (Tabela 1). As três variedades com maior conteúdo de antocianina no suco formaram um único grupo, pelo teste Scott-Knott, diferindo das outras seis variedades (Tabela 1).

Nas Figuras 1a e 2a, pode-se visualizar a coloração amarela da polpa dos frutos e dos sucos dos frutos das nove variedades na condição inicial (sem armazenamento).

Rapisarda \& Giuffrida (1992) observaram valores muito mais altos para os teores de antocianina presentes no suco dos frutos de variedades assemelhadas, quando cultivadas em região de clima mais frio (Sicília, Itália). Foram observados teores entre 196 e 274mg/L de antocianina, no suco dos frutos da variedade Moro; entre 138 e $174 \mathrm{mg} / \mathrm{L}$ de antocianina, para o suco de Sanguinello Moscato, e entre 34 e $98 \mathrm{mg} / \mathrm{L}$, para o suco de Tarocco. Noutro trabalho, Rapisarda et al. (2001) observaram a presença de $231 \mathrm{mg} / \mathrm{L}$ de antocianina no suco de frutos de laranja Moro e $22 \mathrm{mg} / \mathrm{L}$ no suco da variedade Tarocco, quando cultivadas na mesma região.

Diante disto, no presente estudo, pode-se inferir que, provavelmente, o clima da região do município de Cordeirópolis (SP) não possui o número de horas de frio necessário para que os frutos destas variedades de laranja sanguínea acumulem naturalmente antocianinas em grandes quantidades.

Aos 15 dias de armazenamento dos frutos a $10^{\circ} \mathrm{C}$, as variedades aumentaram os teores de antocianina presentes no suco dos frutos de maneira desigual, formando dois grupos distintos: um grupo contendo cinco variedades com valores variando entre 26,8 e 47,3mg/L de antocianina (respectivamente Moro 4 - CN 77 e Moro Palazelli - CN 44) (Tabela 1) e o outro grupo, formado por três variedades que acumularam baixos teores de antocianina no suco e pela laranja Valência, que não acumulou antocianina.

Aos 30 dias de armazenamento, foi possível formar quatro grupos, visto que a Sanguinelli Acirealle (CN 61) não apresentou incremento significativo, enquanto as demais continuaram aumentando o teor do pigmento de forma quase proporcional, conforme pode ser observado na Tabela 1 e Figura 3.

Entre o $45^{\circ}$ e o $60^{\circ}$ dia, o comportamento das variedades também foi diferente (Tabela 1). Algumas tenderam a diminuir o teor de antocianina (Moro 4 - CN 77, Sanguinelli Marrocos - CN 73, Sanguinelli Polidari - CN 74 e Tarocco - CN 67), enquanto outras apresentaram ainda um aumento de forma linear (Moro Palazelli - CN 44 e Moro Acirealle 2 - CN 46) ou cúbica (Sanguinelli Acirealle - CN 61) (Figura 3).

O decréscimo nos teores de antocianina, observado em algumas variedades após o $45^{\circ}$ dia de armazenamento, pode estar relacionado ao avanço do estádio de maturação e ao início do processo de senescência dos frutos. Fato mais facilmente observado na variedade Tarroco Acirealle (CN 65), que, no $60^{\circ}$ 
dia de armazenamento, apresentou frutos em processo adiantado de decomposição.

As variedades Moro foram as que apresentaram as maiores concentrações de antocianina no suco dos frutos, no decorrer e no final do período de armazenamento, seguidas das variedades Sanguinelli (Marrocos e Polidari), excetuando a variedade Sanguinelli Acirealle (CN 61), e, por último, as variedades Tarocco, que apresentaram suco contendo menores teores de antocianina (Tabela 1, Figuras $1 \mathrm{~b}$ e $2 \mathrm{~b}$ ).

Esses resultados foram semelhantes aos obtidos por Rapisarda et al. (2001), que observaram o acúmulo máximo de $130 \mathrm{mg} / \mathrm{L}$ de antocianina em frutos de laranja Tarocco e aproximadamente o dobro nos frutos da variedade Moro, quando submetidos ao armazenamento a $8^{\circ} \mathrm{C}$, durante 40 dias. Lo Piero et al. (2005) também verificaram baixo acúmulo de antocianina nos frutos da variedade Tarocco ( $75 \mathrm{mg}$ de antocianina/ $\mathrm{Kg}$ de polpa), quando conservados a $4^{\circ} \mathrm{C}$, durante até 75 dias.

No presente estudo, apesar de os teores iniciais de antocianina terem sido considerados como baixos em comparação com dados citados na literatura, durante o armazenamento a frio, foi possível observar um forte incremento no teor do pigmento, chegando a valores finais próximos aos obtidos por outros autores. Nos casos das duas variedades de Tarocco, por exemplo, no presente estudo, entre o primeiro dia (dia zero) e o $45^{\circ}$ dia do armazenamento, foram observados incrementos de $215 \mathrm{X}$ a $400 \mathrm{X}$ na concentração inicial do pigmento (Clone 65: de 0,2mg/L, para $43 \mathrm{mg} / \mathrm{L}$ de antocianina e o clone 67: de 0,2mg/L, para 79,7mg/L), enquanto Lo Piero et al. (2005) observaram aumento próximo de 13X, no teor de antocianina, para a mesma variedade, após 75 dias de armazenamento a $4^{\circ} \mathrm{C}$. Neste caso, os autores afirmaram que o armazenamento em câmara fria serviu apenas para completar o teor de antocianina preexistente nos frutos, colhidos de plantas cultivadas em clima frio.

Os dados médios das três avaliações das características físicas e químicas dos frutos das oito variedades de laranja sanguínea e da laranja Valência estão citados nas Tabelas 2 e 3.

As variedades Sanguinelli Marrocos (CN 73) e Sanguinelli Polidari (CN 74) apresentaram frutos significativamente menores (menor altura e largura) e com menor massa que os das demais, resultando em maior número de frutos por caixa de $40,8 \mathrm{~kg}$ (Tabela 2). Além disto, os frutos dessas duas variedades apresentaram suco com acidez significativamente maior e ratio significativamente menor, em comparação com as demais variedades sanguíneas avaliadas, e próximos da laranja Valência (Tabela 3). A variedade Valência é considerada de maturação tardia de frutos com colheita geralmente prevista a partir do mês de novembro, em Cordeirópolis (SP), e o experimento foi iniciado em agosto. Isso demonstra que os frutos dessas duas variedades (CN 73 e CN 74) e da laranja Valência provavelmente ainda não estavam completamente maduros. As outras seis variedades sanguíneas testadas apresentaram frutos com maturação mais precoce que os da laranja Valência.

Rapisarda \& Giuffrida (1992) comprovaram haver uma correlação positiva e significativa entre o estádio de maturação do fruto, expresso pelo ratio do suco (SS/AT), e o conteúdo de antocianina acumulado. Então, no presente estudo, pode-se supor que as variedades Sanguinelli Marrocos (CN 73) e Sanguinelli Polidari (CN 74), que apresentaram suco com menores ratios (Tabela 3), podem ter potencial para acumular maiores teores de antocianina nos frutos e no suco, caso sejam colhidas num estádio mais avançado de maturação.

Pelas Tabelas 2 e 3 , verifica-se que as demais variedades sanguíneas avaliadas podem ser consideradas como semelhantes entre si e adequadas ao consumo como fruta fresca e/ou ao processamento industrial, utilizando-se da laranja Valência como referência.

A análise dos dados das características físicas e químicas de frutos e de sucos por tempo, utilizando-se dos dados médios do conjunto de todas as variedades em cada tempo, demonstrou que houve efeito significativo para o fator tempo de armazenamento somente para as variáveis: largura de frutos ( $\mathrm{F}=5,1$ significativo a $5 \%$ de probabilidade), teor de $\mathrm{SS}(\mathrm{F}=8,6$ significativo a $1 \%$ de probabilidade), acidez ( 8,8 significativo a $1 \%$ de probabilidade) e rendimento de suco ( $\mathrm{F}=5,6$ significativo a $5 \%$ de probabilidade). Então, pode-se afirmar que as demais variáveis avaliadas não foram afetadas durante $o$ armazenamento.

Para a maioria das variedades, observou-se uma tendência à redução, não muito grande, da largura dos frutos durante o armazenamento (Figura 4a), provavelmente devido à perda de água ocorrida através da transpiração durante o armazenamento, o que levou a um ligeiro murchamento dos frutos com conseqüente redução em seu diâmetro.

Para o teor de SS presente no suco dos frutos, em todas as variedades avaliadas, pôde-se observar uma tendência de aumento nos primeiros 30 dias de armazenamento, seguido de redução nos 30 dias subseqüentes (Figura 4b). Como exemplo, tem-se a variedade Moro Acirealle (CN 46), que apresentou teor de SS de $13,2^{\circ}$ Brix no início (dia zero do armazenamento), $14^{\circ}$ Brix aos 30 dias de armazenamento e $11,6^{\circ}$ Brix, na avaliação final, o que demonstrou o avanço da maturação dos frutos (Figura 4b).

Rapisarda et al. (2001) observaram ligeiro aumento no teor de SS nos frutos de Tarocco somente quando armazenados a $8^{\circ} \mathrm{C}$, enquanto para a variedade Moro, essa variável permaneceu inalterada em ambas as temperaturas $\left(8\right.$ e $\left.22^{\circ} \mathrm{C}\right)$, durante todo o período de armazenamento ( 80 dias).

No presente estudo, a acidez titulável do suco das variedades avaliadas apresentou tendência à redução, mas somente entre o $30^{\circ}$ e o $60^{\circ}$ dia de armazenagem, variando entre $1,21 \%, 1,23 \%$ e $0,98 \%$ nas três avaliações dos frutos da variedade Moro-4 (CN 77), por exemplo (Figura 4c). Na mesma figura, verifica-se que as variedades Sanguinelli Marrocos (CN 73) e a Polidari (CN 74), após 30 dias em câmara fria, apresentaram quedas bruscas no teor de acidez, demonstrando o avanço da maturação e o início da senescência, fato também verificado no teor de SS (Figura 4b).

Efeito semelhante foi também observado por Rapisarda et al. (2001), mas com redução contínua desde o início do armazenamento até o final. Segundo Echeverria \& Valishe (1989), uma redução nos níveis de ácido cítrico presentes nos frutos de citros é esperada durante o armazenamento, devido à utilização parcial dos ácidos orgânicos para a produção de energia e para 
a fermentação alcoólica.

$\mathrm{Na}$ Figura 4d, estão citados os dados de rendimento de suco dos frutos de nove variedades de laranja, após a colheita e durante armazenamento a $10^{\circ} \mathrm{C}$, por até 60 dias. Nesta, pode-se verificar que, à exceção da variedade Tarocco Acirealle (CN 65), todas as demais apresentaram tendência de aumento no rendimento de suco no decorrer do armazenamento, com o avanço da maturação.

Rapisarda et al. (2001) obtiveram resultados diferentes, observando reduções no rendimento de suco de duas variedades de laranja Sanguínea durante os primeiros 40 dias de armazenamento, a $8^{\circ} \mathrm{C}$ ou a $22^{\circ} \mathrm{C}$. Para a variedade Tarocco, os

TABELA 1- Médias de teor de antocianina presente no suco dos frutos, de nove variedades de laranja, com avaliações após a colheita e durante o armazenamento a $10^{\circ} \mathrm{C}$, por até 60 dias $^{1}$.

\begin{tabular}{lccccc}
\hline \multirow{2}{*}{ Variedade } & \multicolumn{5}{c}{ Teor de antocianina no suco (mg/L) } \\
\cline { 2 - 6 } & dia 0 & $15^{\circ}$ dia & $30^{\circ}$ dia & $45^{\circ}$ dia & $60^{\circ}$ dia \\
\hline Moro Pallazelli (CN 44) & $8,5 \mathrm{~A}$ & $47,3 \mathrm{~A}$ & $86,8 \mathrm{~A}$ & $82,5 \mathrm{~B}$ & $153,5 \mathrm{~A}$ \\
Moro Acirealle 2 (CN 46) & $13,0 \mathrm{~A}$ & $36,5 \mathrm{~A}$ & $68,3 \mathrm{~B}$ & $159,8 \mathrm{~A}$ & $164,1 \mathrm{~A}$ \\
Moro 4 (CN 77) & $4,3 \mathrm{~B}$ & $26,8 \mathrm{~A}$ & $91,0 \mathrm{~A}$ & $134,5 \mathrm{~A}$ & $128,8 \mathrm{~A}$ \\
Sanguinelli Acirealle (CN 61) & $0,0 \mathrm{~B}$ & $0,2 \mathrm{~B}$ & $0,4 \mathrm{D}$ & $5,6 \mathrm{C}$ & $12,7 \mathrm{~B}$ \\
Sanguinelli Marrocos (CN 73) & $3,8 \mathrm{~B}$ & $32,2 \mathrm{~A}$ & $54,2 \mathrm{~B}$ & $114,9 \mathrm{~B}$ & $79,8 \mathrm{~B}$ \\
Sanguinelli Polidari (CN 74) & $8,9 \mathrm{~A}$ & $28,6 \mathrm{~A}$ & $78,4 \mathrm{~A}$ & $111,9 \mathrm{~B}$ & $79,4 \mathrm{~B}$ \\
Tarocco Acirealle (CN 65) & $0,2 \mathrm{~B}$ & $6,7 \mathrm{~B}$ & $29,0 \mathrm{C}$ & $43,0 \mathrm{C}$ & - \\
Tarocco (CN 67) & $0,2 \mathrm{~B}$ & $12,9 \mathrm{~B}$ & $39,9 \mathrm{C}$ & $79,7 \mathrm{~B}$ & $71,9 \mathrm{~B}$ \\
Valência & $0,0 \mathrm{~B}$ & $0,0 \mathrm{~B}$ & $0,0 \mathrm{D}$ & $0,0 \mathrm{C}$ & $0,0 \mathrm{C}$ \\
\hline Tratamento (Valor F) & $4,53 *$ & $6,0{ }^{* *}$ & $13,4{ }^{* *}$ & $10,1{ }^{* *}$ & $4,1^{*}$ \\
\hline CV (\%) & 90,9 & 37,8 & 26,5 & 28,3 & 46,1 \\
\hline Mén
\end{tabular}

'Média de três amostras, contendo seis frutos cada.

* Significativo ao nível de probabilidade de $5 \%$, pelo teste $\mathrm{F}$.

** Significativo ao nível de probabilidade de $1 \%$, pelo teste $\mathrm{F}$.

Médias seguidas de letras distintas na mesma coluna diferem entre si, pelo teste Scott-Knott, a 5\% de probabilidade.

TABELA 2 - Médias das variáveis referentes à qualidade de frutos de nove variedades de laranja, com avaliações em três períodos (dias 0; 30 e 60).

\begin{tabular}{lccccc}
\hline \multicolumn{1}{c}{ Variedade } & $\begin{array}{c}\text { Massa } \\
(\mathrm{g})\end{array}$ & $\begin{array}{c}\text { Altura } \\
(\mathrm{cm})\end{array}$ & $\begin{array}{c}\text { Largura } \\
(\mathrm{cm})\end{array}$ & $\begin{array}{c}\text { Relação } \\
\mathrm{A} / \mathrm{L}\end{array}$ & $\begin{array}{c}\text { Número de Frutos/ } \\
\text { Caixa }\end{array}$ \\
\hline Moro Pallazelli (CN 44) & $120,0 \mathrm{~B}$ & $6,4 \mathrm{~A}$ & $5,9 \mathrm{~B}$ & $1,1 \mathrm{~A}$ & $340,3 \mathrm{~B}$ \\
Moro Acirealle 2(CN 46) & $122,3 \mathrm{~B}$ & $6,4 \mathrm{~A}$ & $6,0 \mathrm{~B}$ & $1,1 \mathrm{~B}$ & $334,3 \mathrm{~B}$ \\
Sanguin. Acirealle (CN 61) & $126,8 \mathrm{~A}$ & $6,7 \mathrm{~A}$ & $6,0 \mathrm{~B}$ & $1,1 \mathrm{~A}$ & $323,0 \mathrm{~B}$ \\
Tarocco Acirealle (CN 65) & $142,3 \mathrm{~A}$ & $6,6 \mathrm{~A}$ & $6,5 \mathrm{~A}$ & $1,0 \mathrm{~B}$ & $289,5 \mathrm{C}$ \\
Tarocco (CN67) & $146,0 \mathrm{~A}$ & $6,5 \mathrm{~A}$ & $6,4 \mathrm{~A}$ & $1,0 \mathrm{~B}$ & $279,7 \mathrm{C}$ \\
Sanguin. Marrocos (CN 73) & $99,3 \mathrm{C}$ & $6,0 \mathrm{~B}$ & $5,6 \mathrm{C}$ & $1,1 \mathrm{~A}$ & $411,0 \mathrm{~A}$ \\
Sanguin. Polidari (CN 74) & $100,4 \mathrm{C}$ & $6,0 \mathrm{~B}$ & $5,6 \mathrm{C}$ & $1,1 \mathrm{~A}$ & $406,7 \mathrm{~A}$ \\
Moro 4 (CN 77) & $119,3 \mathrm{~B}$ & $6,2 \mathrm{~B}$ & $6,0 \mathrm{~B}$ & $1,0 \mathrm{~B}$ & $342,7 \mathrm{~B}$ \\
Valência & $138,6 \mathrm{~A}$ & $6,5 \mathrm{~A}$ & $6,4 \mathrm{~A}$ & $1,0 \mathrm{~B}$ & $296,3 \mathrm{C}$ \\
\hline Tratamento (Valor F) & $11,6 *$ & $7,7 *$ & $27,2 *$ & $6,0 *$ & $17,6 *$ \\
\hline CV (\%) & 6,6 & 2,6 & 1,7 & 2,2 & 5,6 \\
\hline
\end{tabular}

* Significativo ao nível de probabilidade de $5 \%$, pelo teste $\mathrm{F}$.

Médias seguidas de letras distintas, na mesma coluna, diferem entre si, pelo teste Scott-Knott, a 5\% de probabilidade. autores observaram redução de $47,5 \%$ para $38 \%$, e para a variedade Moro, redução de $40 \%$ para $37 \%$.

Com respeito ao teor de ácido ascórbico presente nos frutos de citros, vários estudos demonstraram a ocorrência de pequena perda, geralmente não-significativa, quando os frutos foram armazenados em diferentes temperaturas (Nagy, 1980, e Rapisarda et al., 2001). No presente estudo, o mesmo fato foi observado, pois os teores de ácido ascórbico presentes nos sucos mantiveram-se com concentração quase constante durante todo o período de armazenamento dos frutos, não sendo verificadas alterações significativas pelo teste Scott-Knott, a 5\% de probabilidade (Tabela 3 ).

TABELA 3 - Médias das variáveis referentes à qualidade do suco de frutos de nove variedades de laranja, com avaliações em três períodos (dias 0; 30 e 60).

\begin{tabular}{|c|c|c|c|c|c|}
\hline Variedade & $\begin{array}{c}\text { Teor de SS } \\
\text { ('brix) }\end{array}$ & Acidez & Ratio & $\begin{array}{c}\text { Ácido ascórbico } \\
\text { (mg/100 mL) }\end{array}$ & $\begin{array}{c}\text { Rendimento de } \\
\text { Suco } \\
(\%)\end{array}$ \\
\hline Moro Pallazelli (CN 44) & $12,9 \mathrm{~A}$ & $1,1 \mathrm{~B}$ & $11,9 \mathrm{~B}$ & $63,2 \mathrm{~B}$ & 50,7 \\
\hline Moro Acirealle 2 (CN 46) & $12,9 \mathrm{~A}$ & $1,2 \mathrm{~B}$ & $10,9 \mathrm{~B}$ & $61,5 \mathrm{~B}$ & 52,3 \\
\hline Sanguin. Acirealle CN 61) & $12,0 \mathrm{~B}$ & $1,0 \mathrm{~B}$ & $11,6 \mathrm{~B}$ & $72,2 \mathrm{~A}$ & 51,2 \\
\hline Tarocco Acirealle ( $\mathrm{CN} 65)$ & $11,8 \mathrm{~B}$ & $0,9 \mathrm{~B}$ & $13,6 \mathrm{~A}$ & $72,4 \mathrm{~A}$ & 47,5 \\
\hline Tarocco (CN 67) & $12,8 \mathrm{~A}$ & $1,0 \mathrm{~B}$ & $12,6 \mathrm{~A}$ & $74,6 \mathrm{~A}$ & 50,4 \\
\hline Sanguin. Marrocos (CN 73) & $12,0 \mathrm{~B}$ & $1,4 \mathrm{~A}$ & $8,3 \mathrm{C}$ & $62,8 \mathrm{~B}$ & 54,6 \\
\hline Sanguin. Polidari (CN 74) & $11,9 \mathrm{~B}$ & $1,4 \mathrm{~A}$ & $8,7 \mathrm{C}$ & $62,7 \mathrm{~B}$ & 52,0 \\
\hline Moro 4 (CN 77) & $12,2 \mathrm{~B}$ & $1,1 \mathrm{~B}$ & $10,7 \mathrm{~B}$ & $64,7 \mathrm{~B}$ & 52,6 \\
\hline Valência & $11,7 \mathrm{~B}$ & $1,6 \mathrm{~A}$ & $7,5 \mathrm{C}$ & $73,4 \mathrm{~A}$ & 54,2 \\
\hline Tratamento (Valor F) & $2,8^{*}$ & $10,8^{*}$ & $12,7^{*}$ & 5,9 * & 0,8 \\
\hline CV (\%) & 4,1 & 9,4 & 9,0 & 5,7 & 6,4 \\
\hline
\end{tabular}

* Significativo ao nível de probabilidade de 5\%, pelo teste $\mathrm{F}$.

Médias seguidas de letras distintas, na mesma coluna, diferem entre si, pelo teste Scott-Knott, a 5\% de probabilidade.
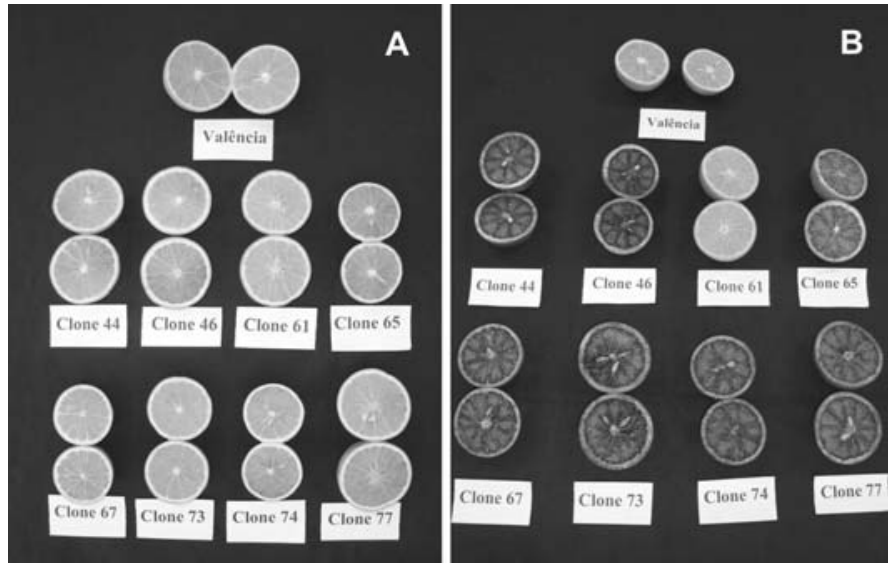

FIGURA 1 - Amostras de frutos de nove variedades de laranja: (A) no dia zero do experimento, e (B) no $45^{\circ}$ dia de armazenamento a $10^{\circ} \mathrm{C}$. 

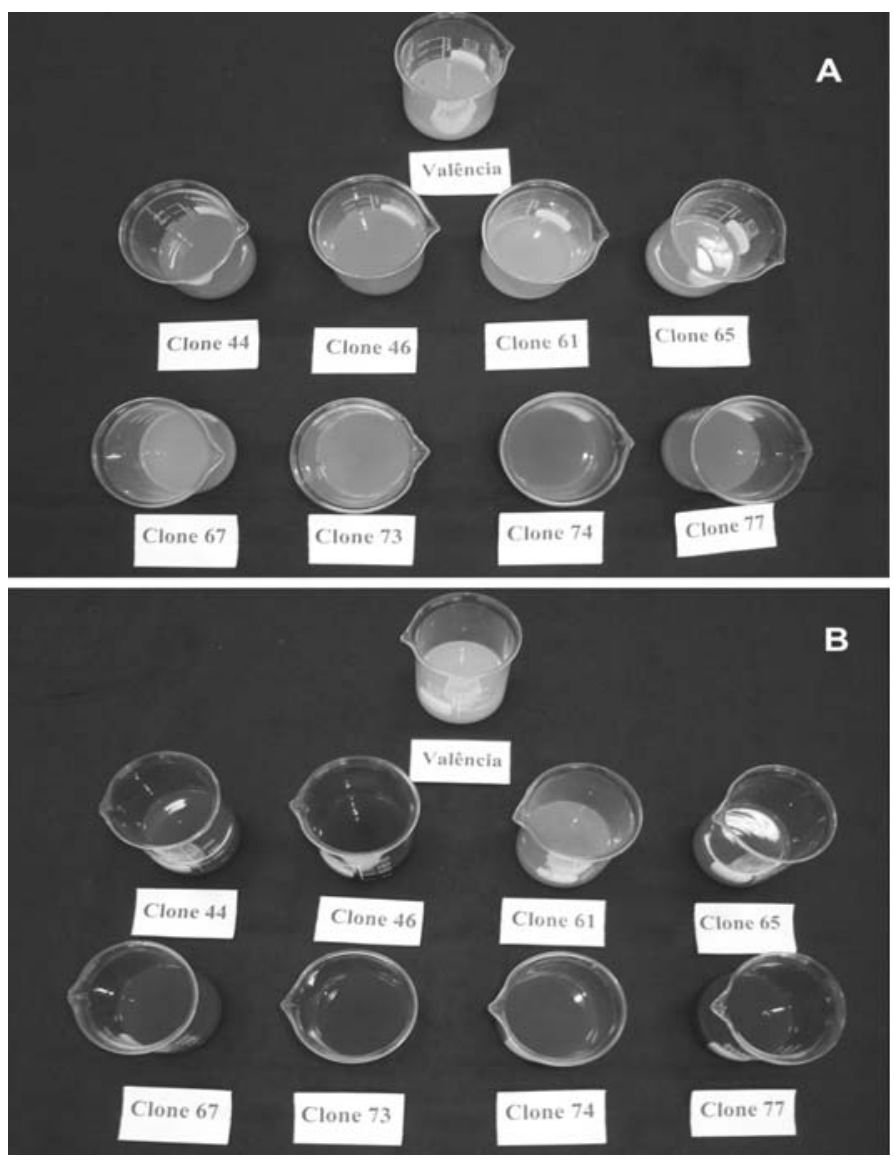

FIGURA 2- Amostras de suco de frutos de nove variedades de laranja: (A) no dia zero do experimento, e (B) no $45^{\circ}$ dia de armazenamento a $10^{\circ} \mathrm{C}$.
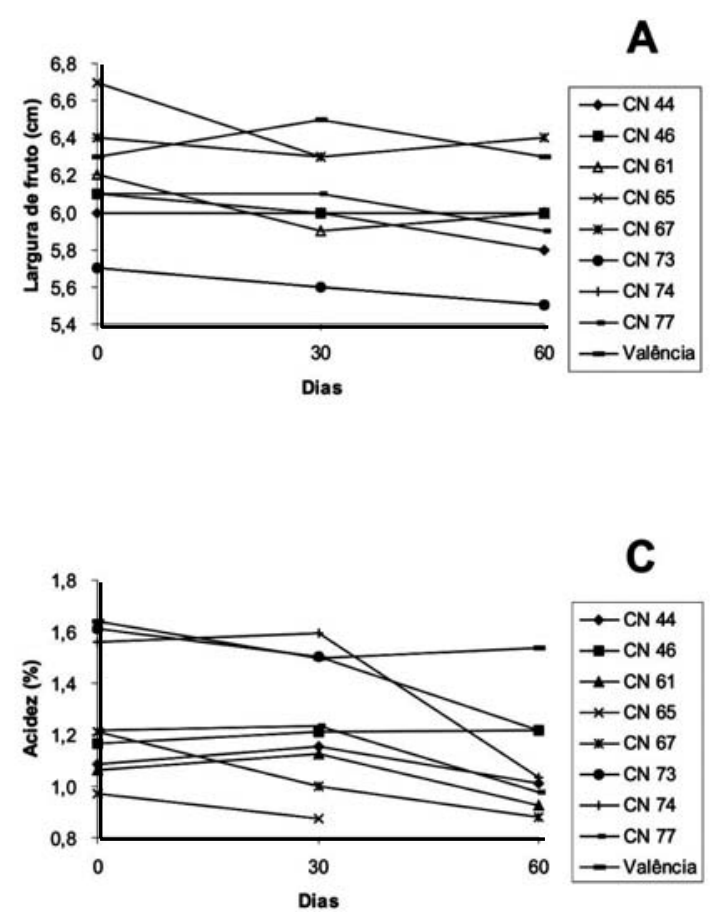

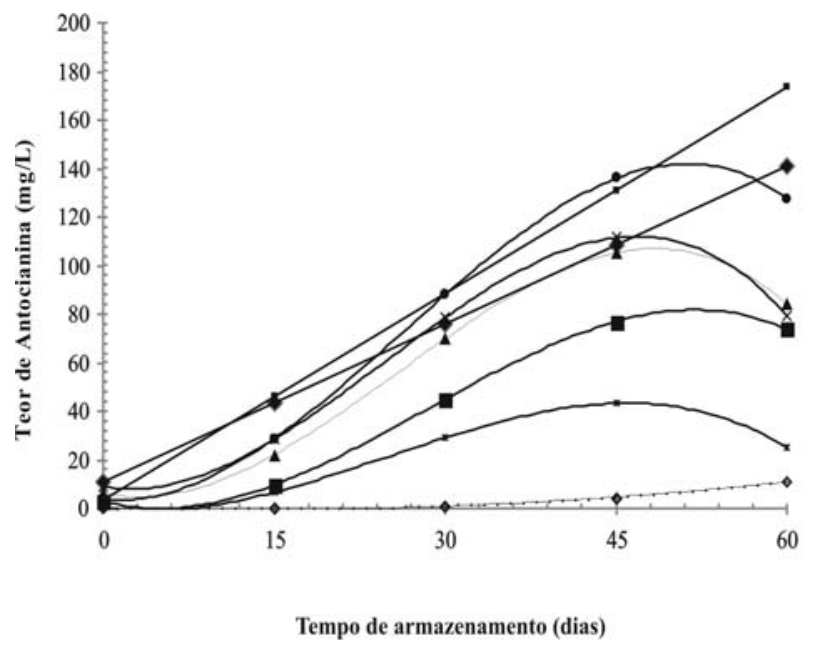

- Moro Pallaz, (CN 44) $\mathrm{Y}=10,64+2,169 \mathrm{x}(\mathrm{R} 2=0,65)$

- Moro Acir. (CN 46) $\mathrm{Y}=3,238+2,837 \times(\mathrm{R} 2=0,68)$

- Sanguin. Acir $(\mathrm{CN} 61) \mathrm{Y}=0,1185-0,0581+0,0016 \times 2+0,00004 \times 3(\mathrm{R} 2=0,94)$

$\times$ Tarocco Acir. $(\mathrm{CN} 65) \mathrm{Y}=0,244-0,6374 \mathrm{x}+0,08896 \times 2-0,00119 \times 3(\mathrm{R} 2=0,91)$

- Tarocco $(\mathrm{CN} 67) \mathrm{Y}=2,902-1,206 \mathrm{x}+0,134 \times 2-0,00157 \times 3(\mathrm{R} 2=0,91)$

$\Delta$ Sanguin. $(\mathrm{CN} 73) \mathrm{Y}=6,391-1,02 \mathrm{x}+0,1705 \times 2-0,0022 \times 3(\mathrm{R} 2=0,90)$

$\times$ Sanguin. (CN 74) $Y=8,995-0,79447 x+0,175 \times 2-0,002337 \times 3(R 2=0,83)$

- Moro $4(\mathrm{CN} 77) \mathrm{Y}=3,833-0,493 \mathrm{x}+0,177 \times 2-0,00224 \times 3(\mathrm{R} 2=0,93)$

FIGURA 3- Curvas de regressão dos teores de antocianina presentes nos sucos de fruto de nove variedades de laranja, em função de tempo de armazenamento a $10^{\circ} \mathrm{C}$.

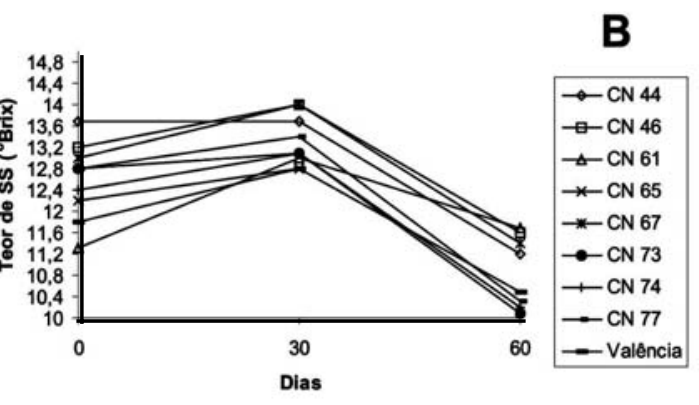

FIGURA 4 - Largura de frutos (A), teor de SS (B), acidez (C) e rendimento de suco (D) de frutos de nove variedades de laranja, após a colheita e durante armazenamento a $10^{\circ} \mathrm{C}$, por até 60 dias. 


\section{CONCLUSÕES}

1-Frutos obtidos de oito variedades de laranja sanguínea cultivadas em Cordeirópolis-SP, acumulam naturalmente baixos teores de antocianinas no suco.

2-O armazenamento a $10^{\circ} \mathrm{C}$, de frutos de variedades de laranja sanguínea, durante até 60 dias, possibilita um acúmulo significativo de antocianinas no suco, porém de maneira desigual, em função da variedade.

3-Dentre as variedades avaliadas, as Moro são as que apresentam suco contendo os maiores teores de antocianinas durante e ao final de 60 dias de armazenamento de frutos, a $10^{\circ} \mathrm{C}$.

4-Nas condições deste experimento, o armazenamento dos frutos das nove variedades, a $10^{\circ} \mathrm{C}$, durante até 60 dias, altera significativamente somente as variáveis: largura de frutos; teor de SS, acidez e rendimento de suco.

\section{REFERÊNCIAS}

BITTERS, W.P. Physical characters and chemical composition as affected by scions and rootstocks. In: SINCLAIR, W.B. (Ed.). The orange: its biochemistry and physiology. Riverside: The University of California, 1961. p. 56-95.

ECHEVERRIA, E.; VALICH, J. Enzymes of sugar and acid metabolism in stored Valencia Oranges. Journal of the American Society for Horticultural Science, Alexandria, n.114, p.445-449, 1989.

FIELD, T.S.; LEE, D.W.; HOLBROOK, N.M. Why leaves turn red in autumn. The role of anthocyanins in senescing leaves of redosier dogwood. Plant Physiology, Washignton, .127, p.566$574,2001$.

INSTITUTO ADOLFO LUTZ Normas analíticas do Instituto Adolfo Lutz. 3.ed. São Paulo, 1985. v.1, 533p.

LO PIERO, A.R.; PUGLISI, I.; RAPISARDA, P.; PETRONE, G. Anthocyanins accumulation and related gene expression in red orange fruit induced by low temperature storage. Journal of Agricultural and Food Chemistry, Washington, n.53, p.90839088, 2005 .
MEREDITH, F.I.; YOUNG, R.H. Effect of temperature on pigment development in red blush grapefruit and ruby blood oranges. In: PROCEEDINGS OF THE FIRST INTERNATIONAL CITRUS SYMPOSIUM, 1., Riverside, 1969. Proceedings... Riverside: University of California, 1969. p.271-276.

NAGY, S. Vitamin C contents of citrus fruit and their products: A review. Journal of Agricultural and Food Chemistry, Washington, n.187, p.530-534, 1980.

RAPISARDA, P.; FANELLA, F.; MACCARONE, E. Reliability of analytical methods for determining anthocyanins in blood orange juices. Journal of Agricultural and Food Chemistry, Washington, n.48, p.2249-2252, 2000.

RAPISARDA, P.; BELLOMO, S.E.; INTELISANO, S. Storage temperature effects on blood orange fruit quality. Journal of Agricultural and Food Chemistry, Washington, n.49, p.32303235, 2001.

RAPISARDA, P.; GIUFFRIDA, A. Anthocyanins level in Italian blood oranges. In: CONGRESSO INTERNACIONAL DE CITRUS, 7., 1992, Acireale. Proocedings... Acireale: International Society of Citriculture, 1992. p.1130-1133.

REED, J.B.; HENDRIX JR., C.M.; HENDRIX, D.L. Quality control manual for citrus processing plants. Safety Harbor: Intercit, 1986. v.1,250p.

ROSS, J.A.; KASUM, C.M. Dietary flavonoids: bioavailability, metabolic effects, and safety. Annual Review of Nutrition, Palo Alto, n.22, p.19-34, 2002.

SAUNT, J. Citrus varietes of the world. Nowich: Sinclair International, 1990. 128p.

WINKEL-SHIRLEY, B. Flavonoid biosynthesis, a colourful model for genetics, biochemistry, cell biology, and biotechnology. Plant Physiology, Minneapolis, n.126, p.485-493, 2001. 